\title{
Preclinical Assessment of Ketamine
}

\author{
Cheng Wang, ${ }^{1}$ Fang Liu, ${ }^{1}$ Tucker A. Patterson, ${ }^{1}$ Merle G. Paule ${ }^{1}$ \& William Slikker $\mathrm{Jr}^{2}$ \\ 1 Division of Neurotoxicology, National Center for Toxicological Research (NCTR)/FDA, Jefferson, AR, USA \\ 2 Office of the Director, National Center for Toxicological Research (NCTR)/FDA, Jefferson, AR, USA
}

\section{Keywords}

Antioxidants; Development; Ketamine; Neurodegeneration; Neuroprotection; NMDA receptor; Reactive oxygen species.

\section{Correspondence}

Cheng Wang, M.D., Ph.D., National Center for Toxicological Research, HFT-132, Food and Drug Administration, Jefferson, AR 720799501, USA.

Tel.: +870-543-7259;

Fax: +870-543-7745;

E-mail: Cheng.Wang@fda.hhs.gov

Received 15 November 2012; revision 22

January 2013; accepted 26 January 2013.

\begin{abstract}
SUMMARY
Ketamine is used as a general anesthetic, and recent data suggest that anesthetics can cause neurodegeneration and/or neuroprotection. The precise mechanisms are not completely understood. This review is to examine the work on ketamine and to address how developmental biology may be utilized when combined with biochemical, pathological, and pharmacokinetic assessments to produce a bridging model that may decrease the uncertainty in extrapolating preclinical data to human conditions. Advantages of using preclinical models to study critical issues related to ketamine anesthesia have been described. These include the relationships between ketamine-induced neurotoxicity/protection and the preclinical models/approaches in elucidating mechanisms associated with ketamine exposure. The discussions focus on the following: (1) the doses and time-course over which ketamine is associated with damage to, or protection of, neural cells, (2) how ketamine directs or signals neural cells to undergo apoptosis or necrosis, (3) how such exposures can trigger mitochondrial dysfunction, (4) how antioxidants and knockdowns of specific transcription modulators or receptors affect neurotoxicity induced by ketamine, and (5) whether the potential neural damage can be monitored after ketamine exposure in living animals using positron emission tomography.
\end{abstract}

doi: $10.1111 /$ cns.12079

\section{Introduction}

Ketamine, a noncompetitive NMDA receptor antagonist, is used primarily in adult, pediatric [1], and veterinary [2] medicine. It is also highly abused for its hallucinogenic and out-of-body experiences [3] and has proven useful in the study of psychiatric disorders [4-6]. At clinically relevant concentrations, ketamine acts to block the NMDA receptor, a subtype of glutamate receptor which is involved in a variety of processes including the following: development and differentiation of the nervous system; learning and memory; and synaptic plasticity [7-10]. NMDA receptors, along with other glutamate receptors, are abundantly expressed in the developing brain and are excitatory on neurons that play key roles in many physiological and pathological processes.

Noncompetitive antagonism of NMDA receptors is thought to be the mechanism by which ketamine produces its primary therapeutic effect: It is also thought to result in ketamine's antiinflammatory activity [11]. Interest in ketamine has increased in recent years as it has been shown to block neuronal death caused by excitotoxic mechanisms [12].

In contrast, these receptors are well-known mediators of neuronal cell death that occurs in a variety of neuropathological conditions [4,13-15]. A growing body of data indicates that ketamine may cause neuronal damage in several major brain regions in animal models including rodents and nonhuman primates, during certain periods of development, particularly the brain growth spurt [16-19]. It has been reported that NMDA receptor NRI expression in ketamine-treated rat pup brains is significantly higher than in controls $[18,20,21]$. It has been postulated that this up-regulation of the NMDA receptor is responsible for or at least contributes to ketamine-induced neurotoxicity because it allows for a toxic accumulation of intracellular calcium once ketamine is washed out of the system.

This review will focus on the characteristics of the toxic and protective effects of ketamine as a function of concentration, duration, and route of administration, receptor subtypes activated, cell type affected, and stage of development at the time of exposure. Also, this review will address the issue of how the tenets of biology can be combined with biochemical, pathological, and pharmacokinetic assessments to produce a bridging model that may decrease the uncertainty associated with the process of extrapolating preclinical ketamine data to the clinical situation.

\section{Potential Roles of Ketamine in Neuroprotection and Anti-Inflammation}

Cognitive deficits are commonly observed following premature birth [22-24]. However, it remains unclear how these early neuroanatomical alterations in the immature brain lead to the cognitive differences observed between preterm and term infants $[25,26]$. A recent publication explored whether ketamine's noncompetitive antagonism of the NMDA receptor could be the 
underlying mechanism for its primary therapeutic and/or antiinflammatory effects [27]. In these experiments, neonatal rats were repeatedly exposed to subcutaneous injections: $4 \%$ formalin into the forepaws to induce inflammatory pain, ketamine prior to formalin injections, ketamine alone, or left untreated (naïve) [27]. Subsequently, when animals were adults, cognitive testing using a delayed nonmatch to sample paradigm for the assessment of working memory in the 8 -arm radial maze was performed. The data indicated that ketamine attenuated the impaired cognitive function resulting from repetitive, neonatal inflammatory pain, presumably by attenuating the associated cell death in the cortex and hippocampus. Therefore, it was concluded that the analgesic and antiinflammatory effects of ketamine can be neuroprotective in a setting of neonatal inflammatory pain.

Also, in a recent clinical study [28], 24 infants were randomized to receive either ketamine $(2 \mathrm{mg} / \mathrm{kg}$ ) or placebo (saline) before cardio-pulmonary bypass for repair of ventricular septal defects. Plasma markers of inflammation and central nervous system injury were then compared at the end of surgery. Spectroscopy before cardio-pulmonary bypass and at the time of hospital discharge was performed in a subset of cases and controls. Cerebral hemodynamics were monitored postoperatively using near-infrared spectroscopy, and neurodevelopmental outcomes were assessed using the Bayley Scales of Infant Development (BSID)-II before and 2-3 weeks after surgery.

Although ketamine treatment was associated with some changes in the magnetic resonance spectroscopy findings and decreases in C-reactive protein levels, no discernible effects on other plasma proteins were observed. No significant differences in BSID-II scores were detected between the ketamine and control groups, although slightly better scores were seen in the ketamine group. Based on the data from this study, it was concluded that there was no convincing evidence that ketamine was either neuroprotective or neurotoxic.

While the above-mentioned findings, particularly those from the clinical study, were not overtly suggestive of either a neuroprotective or neurotoxic effect of ketamine, elements of the study designs and outcomes may provide a framework around which to design future studies. Only an adequately powered, randomized, placebo-controlled study focusing on long-term cognitive and developmental follow-up will be able to definitively answer the questions concerning the effects of pediatric anesthesia on the developing CNS. As it is not likely that such studies will be conducted in populations of human infants, much of this work will necessarily be carried out in animal models. Due to the complexity of the primate brain, the monkey is often the model of choice for neurological and behavioral experiments $[18,19,28]$.

\section{Ketamine-Induced Neurotoxicity During Development}

There is mounting and convincing evidence from animal models that anesthetics in common clinical use are neurotoxic to the developing brain; accumulated data indicate the involvement of NMDA-type glutamate receptors in these effects [16,29-32]. Glutamatergic transmission is mediated by receptor families that are classified as ionotropic (iGluRs) or metabotropic (mGluRs) receptors. iGluRs are ligand-gated ion channels that are subclassified into the following groups based upon their ligandbinding properties: N-methyl-D-aspartate (NMDA); alpha-amino3-hydroxy-5-methyl-4-isoxazole propionate (AMPA); kainate (KA). NMDA receptors are heteromeric complexes composed of obligatory NR1 subunits as well as subunits from the NR2 subfamily (NR2A, NR2B, NR2C, NR2D) or the NR3 subfamily (NR3A or NR3B) [33-36]. Various combinations of subunits generate a large number of different NMDA receptors with differing pharmacological and biological properties. NMDA receptors are excitatory on neurons that play key roles in many physiological and pathological processes and are well-known mediators of neuronal cell death in numerous neuropathological conditions [4,13-15].

Ketamine is distributed rapidly after administration with a bioavailability of $93 \%$ [37]. In a previous study in the rat [20], brain and plasma ketamine levels were found to be highest 5 min after ip administration, after which concentrations decreased to undetectable levels approximately $6 \mathrm{~h}$ after the last ketamine injection. Ketamine levels in brain tissue were generally lower than those seen in plasma. These data demonstrated that ketamine clearance from plasma and brain is very rapid; findings which are consistent with previous reports that ketamine is rapidly distributed [37] with a mean terminal half-life of $186 \pm 10 \mathrm{~min}$ [38]. Although the concentrations of ketamine in plasma and brain were maintained at relatively stable levels over the course of several injections repeated every $2 \mathrm{~h}$, no significant neuroapoptotic effects were detected for up to $4 \mathrm{~h}$ after the last ketamine injection. In contrast, beginning approximately $6 \mathrm{~h}$ and lasting for up to $18 \mathrm{~h}$ following the last ketamine injection, when plasma and brain levels had decreased to virtually zero, enhanced apoptosis was apparent. These data suggest that the enhanced apoptotic cell death associated with ketamine exposure is not directly associated with the in situ blood and brain ketamine levels at the time of cell death, but likely reflects some indirect or compensatory mechanisms.

Anesthetic drugs also produce other dose-dependent cellular effects $[31,32,39]$. Ketamine may act as an antiinflammatory agent at sub-anesthetic concentrations [40,41], whereas higher concentrations produce nonspecific cytostatic effects [42]. High doses of ketamine can also promote seizures [43], a property shared by other anesthetics [44]. In an in vivo rodent study [20], no significant increase in apoptotic neurodegeneration was detected in animals exposed to single or multiple (three or six) injections of 5 or $10 \mathrm{mg} / \mathrm{kg}$ ketamine. However, significant increases in apoptotic neurodegeneration were observed in layers II and III of the frontal cortex and several other major brain regions including the striatum, hippocampus, thalamus, and amygdala in animals treated with six injections of $20 \mathrm{mg} / \mathrm{kg}$ ketamine, as revealed by caspase- 3 immunostaining. These data are consistent with other reports that exposure of the developing brain to NMDA antagonists results in widespread and dose-dependent apoptotic neurodegeneration $[16,30,45,46]$. These data also suggested that the frontal cortex is the brain region most vulnerable to ketamine-induced neurotoxicity.

The first report demonstrating ketamine-induced neuronal cell death in nonhuman primates exposed perinatally to anesthetics was published in 2007 [18]. The neurotoxic effects of ketamine were assessed several hours after the end of hours-long 
intravenous infusions. The findings were interpreted in the context of the hypothesis that prolonged exposure to ketamine induces a compensatory up-regulation of the NMDA receptor, causing neurons to be more vulnerable to the excitotoxic effects of endogenous glutamate after ketamine has been cleared from the system. A 24-hour ketamine infusion was shown to produce a large increase in the number of TUNEL-positive cells in monkeys exposed on postnatal day (PND) 5. The degree to which the nervous system is susceptible or resistant to neurotoxic insults is highly dependent upon its stage of development. In addition to assessing the neurotoxic effects of ketamine in PND 5 monkeys, gestational day (GD) 122 and PND 35 monkeys were also evaluated [18]. As seen with the PND 5 monkeys, GD 122 fetuses also showed clear ketamine-induced neuronal cell damage, whereas PND 35 monkeys did not. GD 122 fetuses and PND 5 neonates, thus, are more sensitive to ketamine-induced cell death than PND 35 monkeys, an age at which less synaptogenesis is occurring. Although a complete understanding of the developmental stages during which nervous system cells are sensitive to ketamine in the primate is not possible from these few early studies, it is apparent that rhesus monkeys are sensitive during the last $25 \%$ of gestation (term is 165 days) to sometime before PND 35. While determining equivalent stages of development between humans and animal models is critical for the extrapolation of safety assessment data, it is also not an easy or exact process. It is generally believed that the nonhuman primate fetus and the human fetus are more similar with respect to stage of maturation at birth than are the rat and the human: Rats are much more immature at birth. Both humans and rhesus monkeys are born with their eyes open, whereas newborn rat pups are not. At PND 7, the rat pup is more similar in maturation to a monkey late in gestation than to a neonatal monkey. According to a recent review [47], the GD 123 monkey fetus is roughly equivalent to a GD 199 human fetus-as determined by cortical development - and both are in the range of $75-80 \%$ of normal term. NMDA receptor-binding sites in the human fetal brain are present by GD 115, increase until GD 140150 and then decrease slightly by GD 168-182 [48]. The localization of NMDA receptors in monkey cortex is also similar to that observed in humans [49].

There is no doubt that prolonged bouts of anesthesia in perinatal rat pups or neonatal monkeys lead to accelerated neurodegeneration. It is proposed that the anesthetic-induced neurotoxicity depends upon the concentration of drugs used, the duration of exposure, the route of administration, the receptor subtype activated, the animal species, and the stage of development or maturity at the time of exposure. These facts are important because exposure concentrations and durations can be utilized to identify thresholds of exposure for producing neurotoxic effects in the developing nervous system.

\section{Advanced Preclinical Research Models and Approaches for Studying the Adverse Effects of Ketamine Anesthesia}

Several studies have demonstrated that ketamine causes neuronal cell death in important brain areas in animals during the brain growth spurt [16-19]. Apoptosis is a common mechanism underlying ketamine-induced neuronal cell death in rodents $[20,50]$. Previous work based on mRNA levels showed that NMDA receptor NRl expression in ketamine-treated rat pup brains was significantly higher than in controls $[18,20,21]$ and subsequent work also showed altered expression levels of the NMDA receptor NR2 family, including NR2A and NR2C [21], after repeated ketamine exposure. This evidence of NMDA receptor upregulation suggests that, upon removal of ketamine from the extracellular milieu, the now upregulated NMDA receptor population (a probable compensation for prolonged NMDA receptor blockade) will "over" respond to normal levels of extracellular glutamate, resulting in glutamatergic excitotoxicity.

To determine whether the upregulated NMDA receptor expression in ketamine-exposed neurons is of functional significance, a recent study [51] examined cytosolic calcium concentrations using a fluorescent calcium indicator [Fura-2-acetoxymethyl (Fura-2 AM)], which diffuses across the cell membrane and is deesterified by cellular esterases to yield Fura-2-free acid [52]. Utilizing a primary neuronal culture system, it was demonstrated that ketamine exposure has a significant impact on subsequent intracellular $\mathrm{Ca}^{2+}$ homoeostasis: The amplitude of calcium influx caused by activating concentrations of NMDA was significantly increased in neurons from ketamine-exposed cultures compared with neurons from control cultures [51]. The NMDA-elicited increases in intracellular $\mathrm{Ca}^{2+}$ were blocked by chelation of extracellular $\mathrm{Ca}^{2+}$ with ethylene glycol tetraacetic acid (EGTA), clearly demonstrating that the NMDA-evoked increases in intracellular calcium originated from an extracellular source, rather than from a depletion or release of calcium from the endoplasmic reticulum. Although calcium is necessary for cell growth, survival, and normal functioning, it can be neurotoxic when present in excess [53]. As ketamine has a well-defined effect on the NMDA receptor at anesthetic concentrations [54], these data provide further support for the hypothesis that enhanced NMDA-type glutamate receptor expression (compensatory up-regulation after prolonged NMDA receptor blockade) promotes the specific signal transduction that plays a critical role in ketamine-induced neurotoxicity.

Meanwhile, advances in our understanding of stem cell biology and neuroscience have opened up new avenues of research for detecting early-life, stress-induced neurotoxicity and for developing potential protective strategies against anesthetic-induced neuronal injuries. Stem cell-derived models, especially human embryonic neural stem cells with their capacity for proliferation and potential for differentiation, provide a great advantage for identifying potential ketamine-induced neurotoxicity. The use of neural stem cell models, especially those of human origin, when combined with calcium imaging and molecular biology approaches, holds great promise for helping to elucidate relevant mechanisms underlying the etiology of the neurotoxicity associated with developmental exposures to general anesthetics and may also help identify ameliorative strategies.

Because the brain growth spurt in both human and nonhuman primates extends over a much longer time period than in the rat, matching the timing of a developmental event in humans and nonhuman primates is less problematic than matching the same between primates and rodents. No other commonly used research animal has a functional fetal-placental unit, a propensity for 
single births and a fetal-to-maternal weight ratio comparable to that of humans. Due to the complexity of the primate brain, the monkey is often the animal of choice for neurotoxicology experiments and, given the protracted period of brain development, the monkey is arguably the very best model for studies of developmental neurotoxicity. The phenomenon of interest in the present discussion has been previously observed in the nonhuman primate, Macaca mulatta $[18,19,28]$. Thus, the relevance of anesthetic-induced neuronal cell death observed in rodent models to children is inferred because similar effects occur in the developing nonhuman primate.

There are two key bridging approaches (cognitive behavioral tests and molecular imaging) being used in efforts to try to predict, in humans, what might be the consequences associated with anesthetic exposure. The National Center for Toxicological Research (NCTR) Operant Test Battery (OTB) has been used in our animal and human research laboratories for a number of years in translational studies of cognitive function [55]. The OTB contains several complex positively reinforced tasks in which correct performance is thought to depend on relatively specific and important brain functions, which include learning, color, and position discrimination, motivation, and short-term memory. Previous experiments from our laboratory have shown that the tasks in the OTB are differentially sensitive to the acute effects of a variety of drugs from different pharmacological classes and that OTB performance by children is not generally distinguishable from that of well-trained rhesus monkeys [55]. The similarity in OTB performance between monkeys and children [56] is of particular importance with regard to extrapolating to humans the neurobehavioral (and possibly neurotoxic) effects of drugs and toxicants as determined in the monkey model. Also, we have demonstrated that early ketamine exposure, in the rhesus model, results in long-term functional deficits [57]. Additionally, the demonstration that several measures of OTB performance correlate highly with measures of intelligence in children [58] serves to highlight the relevance of such measures.

In vivo imaging of rodents, nonhuman primates, and human (both in adults and children) using positron emission tomography (PET) allows for objective and quantitative assessments of functional and molecular targets in a longitudinal manner. When combined with behavioral assessments such as the OTB, PET offers a unique bridging approach allowing insight into "structure and function" issues that are not accessible via other methods. As an extensively studied apoptotic tracer, ${ }^{[18]}$ F-annexin V has been used to label apoptotic neurons in the anestheticexposed brain of rodents [59]. PET imaging utilizing the smaller size probe for apoptosis; ${ }^{[18]}$ F-DFNSH (5-(dimethylamino)- $\mathrm{N}^{\prime}-(4-$ fluorobenzylidene) naphthalene-1-sulfonohydrazide) [60] provides results similar to those seen for ${ }^{[18]} \mathrm{F}$-annexin $\mathrm{V}$ with a higher signal-to-noise ratio. ${ }^{[18]}$ F-FEPPA $\left({ }^{[18]} \mathrm{F}-\mathrm{N}\right.$-2-(2-fluoroethoxy)benzyl)-N-(4-phenoxypyridin-3-yl)acetamide), a recently employed marker of activated microglia, also appears to be suitable for visualizing and quantifying aspects of neurotoxicity (neuroinflammation) and is also applicable to the primate [61]. Utilization of this and hopefully other tracers capable of providing measures of neurotoxicity in human PET imaging will allow investigators to determine whether similar phenomenon occurs in humans.

\section{Antioxidants and Ketamine Neurotoxicity}

It is becoming increasingly apparent that mitochondria lie at the center of the cell death regulation process. In a recent in vitro mechanistic study [51], an increase in the generation of reactive oxygen species (ROS) was associated with the increased $\mathrm{Ca}^{2+}$ influx seen in ketamine-exposed neurons in culture. These ROS appear to originate in mitochondria. Recent evidence suggests that general anesthetics, administered during the peak of synaptogenesis, cause protracted injury to mitochondria including significant enlargement, impairment of their structural integrity, and a decrease in their regional distribution [62]. Along with morphological changes, the general anesthetics also cause functional impairment of immature neuronal mitochondria [63]. Injured mitochondria may be a significant source of ROS [63]. In a mechanistic study [51], ketamine administration markedly elevated both nuclear and mitochondrial levels of 8-oxoguanine. The concordance between elevated 8-oxoguanine levels, enhanced DNA fragmentation and increases in the number of cells with DNA strand breaks following ketamine exposure, suggests key roles for calcium homeostasis and mitochondrial ROS production in inducing neuronal DNA damage and ketamine-induced cell death via apoptotic pathways.

ROS generated by mitochondria are not just toxic by-products of respiration; they are also important for cell signaling [64,65]. Calcium homeostasis is one determinant of ultimate cell survival: Excessive calcium sequestration by mitochondria can produce injury leading to respiratory inhibition, uncoupling of oxidative phosphorylation, and ultimately, the release of cytochrome $c$ from the mitochondrial membrane into the cytosol [66-68]. Most of the mitochondrial effects of $\mathrm{Ca}^{2+}$ require its entry across the mitochondrial double membrane into the matrix. Although the mitochondrial outer membrane was thought to be permeable to $\mathrm{Ca}^{2+}$, recent studies suggest that the outer membrane voltagedependent anion channel is a ruthenium red (RuRed)-sensitive $\mathrm{Ca}^{2+}$ channel that serves to regulate $\mathrm{Ca}^{2+}$ entry into the mitochondrial inter-membrane space [69]. To test whether mitochondrial function is affected by disturbed $\mathrm{Ca}^{2+}$ influx, L-carnitine, an antioxidant dietary supplement, was utilized [51]. L-carnitine plays an integral role in attenuating brain injury associated with mitochondria-related oxidative stress [70]. Cells from forebrain cultures were exposed to ketamine or ketamine plus L-carnitine. After removal of ketamine, cultures were assayed using 8-oxoguanine and Cell Death Detection ELISAs and the Comet (Single-Cell Gel Electrophoresis) assay. The data from all three of these assays indicated that aspects of ketamineinduced DNA damage and neurotoxicity can be effectively blocked by L-carnitine. The neuronal protective mechanism of L-carnitine is very complicated and still unclear. It may involve cell membrane stabilization, increased heat shock protein and superoxide dismutase production and/or decreased expression of iNOS. It is proposed that the protective effects of L-carnitine are likely due to membrane modulation, presumably by reducing ROS generation or increasing ROS scavenging, to preserve mitochondrial membrane integrity, a process thought to be downstream of ketamine-induced receptor alterations and disturbed $\mathrm{Ca}^{2+}$ homeostasis. 
Little is known about the signaling pathway(s) that mediate the postulated roles of altered $\mathrm{Ca}^{2+}$ influx. $\mathrm{Ca}^{2+}$ may enhance ROS output by making the entire mitochondrion work faster and consume more $\mathrm{O}_{2}$. Indeed, mitochondrial ROS generation correlates well with metabolic rate, [71,72] suggesting that faster metabolism simply results in more leakage of electrons from the respiratory chain. In addition, $\mathrm{Ca}^{2+}$ stimulation of nitric oxide synthase [73] generates NO, which inhibits complex IV [74], thus enhancing ROS generation. Importantly, several recent studies using blockers of oxidative stress such as melatonin [75], the superoxide dismutase mimetic, M40403 [76], the NOS inhibitor, 7-nitroindazole [77], hypothermia [78], EUK-134, a synthetic ROS scavenger, or $\mathrm{R}(+)$ pramipexole (PPX), a synthetic aminobenzothiazol derivative that restores mitochondrial integrity [63], have indicated that reduction in oxidative stress may protect the developing animal from anesthetic-induced brain cell death. In addition, Trolox, a ROS scavenger, has also been demonstrated to significantly attenuate ketamine-induced increases in ROS formation, caspase- 3 activity, and cell damage [67].

\section{Conclusion}

This review has described both the toxicity and protective effects of ketamine and indicated that the involvement of ketamine in either toxicity and/or protection may be determined or directed by the dose of ketamine used, the duration of exposure, the route of administration, and the stage of development at the time of exposure.

This review discussed the proposed mechanisms by which prolonged ketamine exposure produces an increase in NMDA receptor expression that allows for a toxic influx of calcium into neurons once ketamine is removed from the system, leading to elevated ROS generation and neuronal cell death. The application of antioxidants such as L-carnitine appears to be promising for preventing or reversing the toxic effects of ketamine.

Application of sophisticated research models such as the nonhuman primate or stem cell-derived models, when combined with advanced research approaches, holds promise for elucidating relevant mechanisms underlying the etiology of the neurotoxicity associated with developmental exposures to ketamine.

\section{Disclaimer}

This document has been reviewed in accordance with United States Food and Drug Administration (FDA) policy and approved for publication. Approval does not signify that the contents necessarily reflect the position or opinions of the FDA. The findings and conclusions in this report are those of the authors and do not necessarily represent the views of the FDA.

\section{Conflict of Interest}

The authors declare no conflicts of interest.

\section{References}

1. Deasy C, Babl FE. Intravenous vs intramuscular ketamine for pediatric procedural sedation by emergency medicine specialists: a review. Paediatr Anaesth 2010;20:787-796.

2. Muir WW. NMDA receptor antagonists and pain: ketamine. Vet Clin North Am Equine Pract 2010;26:565578 .

3. Reynaud-Maurupt C, Bello PY, Akoka S, Toufik A. Characteristics and behaviors of ketamine users in France in 2003. J Psychoactive Drugs 2007;39:1-11.

4. Bubenikova-Valesova V, Horacek J, Vrajova M, Hoschl C. Models of schizophrenia in humans and animals based on inhibition of NMDA receptors. Neurosci Biobehav Rev 2008;32:1014-1023.

5. Machado-Vieira R, Salvadore G, Diazgranados N, Zarate CA Jr. Ketamine and the next generation of antidepressants with a rapid onset of action. Pharmacol Ther 2009;123:143-150.

6. Krystal JH, Mathew SJ, D'Souza DC, Garakani A, Gunduz-Bruce H, Charney DS. Potential psychiatric applications of metabotropic glutamate receptor agonists and antagonists. CNS Drugs 2010;24:669-693.

7. Collingridge GL, Kehl SJ, McLennan H. Excitatory amino acids in synaptic transmission in the Schaffer collateralcommissural pathway of the rat hippocampus. J Physiol 1983;334:33-46.

8. Meldrum B, Garthwaite J. Excitatory amino acid neurotoxicity and neurodegenerative disease. Trends Pharmacol Sci 1990;11:379-387.

9. D'Souza SW, McConnell SE, Slater P, Barson AJ. Glycine site of the excitatory amino acid N-methyl-D-aspartate receptor in neonatal and adult brain. Arch Dis Child 1993;69:212-215.

10. Muller D, Wang C, Skibo G, et al. PSA-NCAM is required for activity-induced synaptic plasticity. Neuron 1996;17:413-422.
11. Bhutta AT, Schmitz ML, Swearingen C, et al. Ketamine as a neuroprotective and anti-inflammatory agent in children undergoing surgery on cardiopulmonary bypass: a pilot randomized, double-blind, placebo-controlled trial. Pediatr Crit Care Med 2012;13:328-337.

12. Anand KJ, Garg S, Rovnaghi CR, Narsinghani U, Bhutta AT, Hall RW. Ketamine reduces the cell death following inflammatory pain in newborn rat brain. Pediatr Res 2007:62:283-290.

13. Kari HP, Davidson PP, Kohl HH, Kochhar MM. Effects of ketamine on brain monoamine levels in rats. Res Commun Chem Pathol Pharmacol 1978;20:475-488.

14. Wakschlag LS, Kistner EO, Pine DS, et al. Interaction of prenatal exposure to cigarettes and MAOA genotype in pathways to youth antisocial behavior. Mol Psychiatry 2010;15:928-937.

15. Medeiros LF, Rozisky JR, de Souza A, et al. Lifetime behavioural changes after exposure to anaesthetics in infant rats. Behav Brain Res 2011;218:51-56.

16. Ikonomidou C, Bosch F, Miksa M, et al. Blockade of NMDA receptors and apoptotic neurodegeneration in the developing brain. Science 1999;283:70-74.

17. Scallet AC, Schmued LC, Slikker W Jr, et al. Developmental neurotoxicity of ketamine: morphometric confirmation, exposure parameters, and multiple fluorescent labeling of apoptotic neurons. Toxicol Sci 2004;81:364-370.

18. Slikker W Jr, Zou X, Hotchkiss CE, et al. Ketamineinduced neuronal cell death in the perinatal rhesus monkey. Toxicol Sci 2007;98:145-158.

19. Zou X, Patterson TA, Divine RL, et al. Prolonged exposure to ketamine increases neurodegeneration in the developing monkey brain. Int J Dev Neurosci 2009a; 27:727-731.

20. Zou X, Patterson TA, Sadovova N, et al. Potential neurotoxicity of ketamine in the developing rat brain. Toxicol Sci 2009b;108:149-158.
21. Shi Q, Guo L, Patterson TA, et al. Gene expression profiling in the developing rat brain exposed to ketamine. Neuroscience 2010;166:852-863.

22. Luciana M, Lindeke L, Georgieff M, Mills M, Nelson CA. Neurobehavioral evidence for working-memory deficits in school-aged children with histories of prematurity. Dev Med Child Neurol 1999;41:521-533.

23. Peterson BS, Vohr B, Kane MJ, et al. A functional magnetic resonance imaging study of language processing and its cognitive correlates in prematurely born children. Pediatrics 2002;110:1153-1162.

24. Peterson BS, Vohr B, Staib LH, et al. Regional brain volume abnormalities and long-term cognitive outcome in preterm infants. JAMA 2000;284:1939-1947.

25. Bhutta AT, Cleves MA, Casey PH, Cradock MM, Anand KJ. Cognitive and behavioral outcomes of school-aged children who were born preterm: a meta-analysis. JAMA 2002;288:728-737.

26. Bhutta AT, Anand KJ. Abnormal cognition and behavior in preterm neonates linked to smaller brain volumes. Trends Neurosci 2001;24:129-130, discussion 31-2.

27. Rovnaghi CR, Garg S, Hall RW, Bhutta AT, Anand KJ. Ketamine analgesia for inflammatory pain in neonatal rats: a factorial randomized trial examining long-term effects. Behav Brain Funct 2008;4:35.

28. Brambrink AM, Evers AS, Avidan MS, et al. Isofluraneinduced neuroapoptosis in the neonatal rhesus macaque brain. Anesthesiology 2010;112:834-841.

29. Choi DW. Glutamate neurotoxicity and diseases of the nervous system. Neuron 1988;1:623-634.

30. Jevtovic-Todorovic V, Hartman RE, Izumi Y, et al. Early exposure to common anesthetic agents causes widespread neurodegeneration in the developing rat brain and persistent learning deficits. $J$ Neurosci 2003;23:876-882.

31. Wang C, Sadovova N, Fu X, et al. The role of the Nmethyl-D-aspartate receptor in ketamine-induced 
apoptosis in rat forebrain culture. Neuroscience 2005:132:967-977.

32. Wang C, Sadovova N, Hotchkiss C, et al. Blockade of Nmethyl-D-aspartate receptors by ketamine produces loss of postnatal day 3 monkey frontal cortical neurons in culture. Toxicol Sci 2006;91:192-201.

33. Furukawa H, Singh SK, Mancusso R, Gouaux E. Subunit arrangement and function in NMDA receptors. Nature 2005; 438: 185-192.

34. Laube B, Kuhse J, Betz H. Evidence for a tetrameric structure of recombinant NMDA receptors. J Neurosci 1998; 18:2954-2961.

35. Premkumar LS, Auerbach A. Stoichiometry of recombinant $\mathrm{N}$-methyl-D-aspartate receptor channels inferred from single-channel current patterns. $J$ Gen Physiol 1997;110:485-502.

36. Ulbrich MH, Isacoff EY. Subunit counting in membranebound proteins. Nat Methods 2007;4:319-321.

37. Grant IS, Nimmo WS, Clements JA. Lack of effect of ketamine analgesia on gastric emptying in man. $\mathrm{Br} \mathrm{J}$ Anaesth 1981;53:1321-1323.

38. Clements JA, Nimmo WS. Pharmacokinetics and analgesic effect of ketamine in man. $\mathrm{Br} J$ Anaesth 1981;53:27-30.

39. Anand KJ, Soriano SG. Anesthetic agents and the immature brain: are these toxic or therapeutic? Anesthesiology 2004;101:527-530.

40. Zilberstein G, Levy R, Rachinsky M, et al. Ketamine attenuates neutrophil activation after cardiopulmonary bypass. Anesth Analg 2002;95:531-536, table of contents.

41. Roytblat L, Talmor D, Rachinsky M, et al. Ketamine attenuates the interleukin-6 response after cardiopulmonary bypass. Anesth Analg 1998;87:266-271

42. Lewis E, Rogachev B, Shaked G, Douvdevani A. The in vitro effects of ketamine at large concentrations can be attributed to a nonspecific cytostatic effect. Anesth Analg 2001;92:927-929.

43. Lees GJ. Influence of ketamine on the neuronal death caused by NMDA in the rat hippocampus. Neuropharmacology 1995;34:411-417.

44. Roytblat L, Bear R, Gesztes T. Seizures after pentazocine overdose. Isr J Med Sci 1986;22:385-386.

45. Ikonomidou C, Bittigau P, Koch C, et al. Neurotransmitters and apoptosis in the developing brain. Biochem Pharmacol 2001;62:401-405.

46. Olney JW, Wozniak DF, Jevtovic-Todorovic V, Farber NB, Bittigau P, Ikonomidou C. Drug-induced apoptotic neurodegeneration in the developing brain. Brain Pathol 2002;12:488-498.

47. Clancy B, Finlay BL, Darlington RB, Anand KJ. Extrapolating brain development from experimental species to humans. Neurotoxicology 2007;28:931-937.

48. Haberny KA, Paule MG, Scallet AC, et al. Ontogeny of the N-methyl-D-aspartate (NMDA) receptor system and susceptibility to neurotoxicity. Toxicol Sci 2002;68:9-17.

49. Huntley GW, Vickers JC, Morrison JH. Quantitative localization of NMDAR1 receptor subunit immunoreactivity in inferotemporal and prefrontal association cortices of monkey and human. Brain Res 1997; 749:245-262.

50. Yon JH, Daniel-Johnson J, Carter LB, Jevtovic-Todorovic V. Anesthesia induces neuronal cell death in the developing rat brain via the intrinsic and extrinsic apoptotic pathways. Neuroscience 2005; 135:815-827.

51. Liu F, Patterson TA, Sadovova N, et al. Ketamine-induced neuronal damage and altered $\mathrm{N}$-methyl-D-aspartate (NMDA) receptor function in rat primary forebrain culture. Toxicol Sci 2013;131:548-557.

52. Barreto-Chang OL, Dolmetsch RE. Calcium imaging of cortical neurons using Fura-2 AM. J Vis Exp 2009;23:1067.

53. Lynch DR, Guttmann RP. Excitotoxicity: perspectives based on N-methyl-D-aspartate receptor subtypes. $J$ Pharmacol Exp Ther 2002;300:717-723.

54. Irifune $M$, Shimizu $T$, Nomoto $M$, Fukuda T. Ketamineinduced anesthesia involves the $\mathrm{N}$-methyl-D-aspartate receptor-channel complex in mice. Brain Res 1992;596: 1-9.

55. Paule MG. Validation of a behavioral test battery for monkeys. In: Buccafusco JJ, ed. Methods of behavioral analysis in neuroscience. Boca Raton, FL: CRC Press LLC 2001;281-294.

56. Paule MG, Forrester TM, Maher MA, Cranmer JM, Allen RR. Monkey versus human performance in the NCTR Operant Test Battery. Neurotoxicol Teratol 1990;12:503507.

57. Paule MG, Li M, Allen RR, et al. Ketamine anesthesia during the first week of life can cause long-lasting cognitive deficits in rhesus monkeys. Neurotoxicol Teratol 2011;33:220-230.

58. Paule MG, Chelonis JJ, Buffalo EA, Blake DJ, Casey PH. Operant test battery performance in children: correlation with IQ. Neurotoxicol Teratol 1999;21:223-230.

59. Zhang X, Paule MG, Newport GD, et al. A minimally invasive, translational biomarker of ketamine-induced neuronal death in rats: microPET Imaging using $18 \mathrm{~F}-$ annexin V. Toxicol Sci 2009;111:355-361.

60. Zhang $X$, Paule MG, Newport GD, et al. MicroPET imaging of ketamine-induced neuronal apoptosis with radiolabeled DFNSH. J Neural Transm 2011;118:203-211.

61. Zhang X, Paule MG, Newport GD, et al. MicroPET/CT imaging of [18F]-FEPPA in the nonhuman primate: a potential biomarker of pathogenic processes associated with anesthetic-induced neurotoxicity. ISRN Anesthesiology 2012; doi: 10.5402/2012/261640.

62. Sanchez V, Feinstein SD, Lunardi N, et al. General anesthesia causes long-term impairment of mitochondrial morphogenesis and synaptic transmission in developing rat brain. Anesthesiology 2011;115:992-1002.

63. Boscolo A, Starr JA, Sanchez V, et al. The abolishment of anesthesia-induced cognitive impairment by timely protection of mitochondria in the developing rat brain: the importance of free oxygen radicals and mitochondrial integrity. Neurobiol Dis 2012;45:1031-1041.

64. Brookes P, Darley-Usmar VM. Hypothesis: the mitochondrial $\mathrm{NO}(*)$ signaling pathway, and the transduction of nitrosative to oxidative cell signals: an alternative function for cytochrome C oxidase. Free Radic Biol Med 2002;32:370-374.

65. Brookes PS, Levonen AL, Shiva S, Sarti P, Darley-Usmar VM. Mitochondria: regulators of signal transduction by reactive oxygen and nitrogen species. Free Radic Biol Med 2002;33:755-764.

66. Blaylock M, Engelhardt T, Bissonnette B. Fundamentals of neuronal apoptosis relevant to pediatric anesthesia. Paediatr Anaesth 2010;20:383-395.

67. Bosnjak ZJ, Yan Y, Canfield S, et al. Ketamine induces toxicity in human neurons differentiated from embryonic stem cells via mitochondrial apoptosis pathway. Curr Drug Saf 2012;7:106-119.

68. Zhang Y, Dong Y, Wu X, et al. The mitochondrial pathway of anesthetic isoflurane-induced apoptosis. $J$ Biol Chem 2010;285:4025-4037.

69. Gincel D, Zaid H, Shoshan-Barmatz V. Calcium binding and translocation by the voltage-dependent anion channel: a possible regulatory mechanism in mitochondrial function. Biochem $J$ 2001;358:147-155.

70. Zou X, Sadovova N, Patterson TA, et al. The effects of Lcarnitine on the combination of, inhalation anestheticinduced developmental, neuronal apoptosis in the rat frontal cortex. Neuroscience 2008;151:1053-1065.

71. Sohal RS, Allen RG. Relationship between metabolic rate, free radicals, differentiation and aging: a unified theory. Basic Life Sci 1985;35:75-104.

72. Perez-Campo R, Lopez-Torres M, Cadenas S, Rojas C, Barja $G$. The rate of free radical production as a determinant of the rate of aging: evidence from the comparative approach. J Comp Physiol B 1998;168:149158.

73. Alderton WK, Cooper CE, Knowles RG. Nitric oxide synthases: structure, function and inhibition. Biochem $J$ 2001;357:593-615.

74. Cleeter MW, Cooper JM, Darley-Usmar VM, Moncada S, Schapira AH. Reversible inhibition of cytochrome c oxidase, the terminal enzyme of the mitochondrial respiratory chain, by nitric oxide. Implications for neurodegenerative diseases. FEBS Lett 1994;345:50-54

75. Yon JH, Carter LB, Reiter RJ, Jevtovic-Todorovic V. Melatonin reduces the severity of anesthesia-induced apoptotic neurodegeneration in the developing rat brain Neurobiol Dis 2006;21:522-530

76. Wang C, McInnis J, West JB, et al. Blockade of phencyclidine-induced cortical apoptosis and deficits in prepulse inhibition by M40403, a superoxide dismutase mimetic. J Pharmacol Exp Ther 2003;304:266-271.

77. Wang C, Sadovova N, Patterson TA, et al. Protective effects of 7-nitroindazole on ketamine-induced neurotoxicity in rat forebrain culture. Neurotoxicology 2008;29:613-620.

78. Friedman R. Hypothermia approach may avoid apoptosis from anesthesia in children. Neurology Today 2009;9:1920. 